Neurosurg Focus 12 (4):Article 9, 2002, Click here to return to Table of Contents

\title{
What neurosurgeons should do to succeed in tomorrow's scientific and socioeconomic environment
}

\author{
James I. Ausman, M.D., Ph.D., And Ronald P. Pawl, M.D. \\ Department of Neurosurgery, University of Illinois at Chicago, Illinois
}

\begin{abstract}
There will be major scientific advances and socioeconomic changes in the 21 st century that will influence the development of medicine and neurosurgery. These changes will affect those in academic medical centers and the private practitioners of medicine and neurosurgery. Neurosurgeons' philosophy and practice methods must adapt to these trends. Because of the continuing growth in scientific knowledge and the rapid spread of communications of all types, physicians will best work in groups and teams. These group forces will require the physicians to surrender some independence to gain the power of the integrated knowledge and political and social force of a group. Graduate and postgraduate education programs will also change to adapt to these new realities. Those who understand these new shifts will be the most successful in establishing and conducting practices in academic centers and private practice.
\end{abstract}

KEY WORDS • neurosurgery • science • socioeconomics

Physicians worldwide have been selected from among the most capable and intelligent people to enter their profession. Their education takes years, and most not only look forward to the personal satisfaction of caring for patients but also to financial security. The globalization of economics, however, has placed industry worldwide in competition to produce the lowest-cost products. Driven by expanding populations, health care expenses have risen beyond the ability of industry and government to afford them. In the US we are conditioned to desire the latest medical treatments in the hope of prolonging life, which are regarded as valuable in this and other industrialized cultures. New restrictions on government-sponsored health care expenditures or reduced payments by third parties hired by industry, have limited the reimbursement for physicians, threatening their long-planned careers in terms of financial security and satisfaction. Physicians are reluctant to revise long-set career goals and behavior, and they are frustrated by the socioeconomic changes influencing medicine. Some retire early; others become frustrated in practice, and seek security as salaried employees of large health care systems or insurance plans; but few adapt and change with the new environment.

Abbreviation used in this paper: US = United States.
The purpose of this paper is to outline for neurosurgeons and other physicians the influences leading to changes in the practice of medicine in this century and to propose solutions to allow future success in this new environment.

\section{SCIENTIFIC TRENDS SHAPING THE FUTURE OF MEDICINE AND NEUROSURGERY}

\section{Biological Advances}

There are two major areas of scientific growth: biology and technology. In biological science, the extensive research into the molecular events of the cell and the sequencing of the genome will lead to major changes in the practice of medicine. ${ }^{9}$ These discoveries will change how we treat cancers of the central nervous system and other diseases. Surgical debulking of brain tumors, which has been performed for the last 100 years, aided by radio- and chemotherapy, has failed to control intracranial neoplasms and often results in serious morbidity. Targeted molecular therapies will become more successful and will prevail in treating cancer and other diseases. Furthermore, these molecular advances will allow us to understand the biochemical sequence of events leading to ischemia-induced cell death. This information will influence the way we treat 


\section{J. I. Ausman and R. P. Pawl}

cerebral ischemia, edema, and trauma. Neurosurgeons will have to be knowledgeable about the metabolic changes occurring in each of these conditions. Specific biochemical treatments will exist for different phases of the metabolic chain reaction that occur with cell injury underlying all of these diseases. We have seen evidence of this in the recent discoveries of the multiple posttrauma phases through which the brain cells pass. ${ }^{7}$

No less important an advance will be cell transplantation, which will restore functions that are lost due to trauma-related cell death, infarction, and degenerative diseases. ${ }^{8,12}$ Neurosurgeons must be participants in this research and must understand all of the genetic, behavioral, and immunological phenomena involved to achieve success, as did transplant surgeons 25 years ago. If not, the neurosurgeon will cling to a few technical procedures, becoming marginalized while new advances allow other practitioners to take over their patients and treatments. The rise of those performing interventional treatments for aneurysms is an example.

\section{Technological Advances}

In technology, major advances in neuroimaging will continue to enhance insights into the function of the brain. We will be able to visualize fiber tracts and determine their function noninvasively in each individual. ${ }^{6}$ There will be metabolic maps of the brain indicating differences between ill and healthy people. ${ }^{5}$ For example, the differences in each patient's reaction to pain will be understood because neuroimaging (positron emission tomography and magnetic resonance imaging) reveals the biochemical, fiber tract, and synaptic diversities among patients. ${ }^{13}$ This information will be used to guide computerized surgical approaches to lesions, which will minimize morbidity. Differences among individuals in transmitter concentrations, determined by neuroimaging, will become the basis for selective drug modeling and therapy that will be individually tailored. ${ }^{5,13}$ The development of nanoscience will allow the creation of implantable prostheses for hearing, vision, and perhaps other functions. ${ }^{1,10}$

\section{Medical Specialization}

It is and will be impossible for one person to know and understand all the available information. Because of the increasing rate of scientific discovery, the amount of medical-related data doubles every 8 years. ${ }^{3}$ This increase of scientific information will continue at an asymptotic rate, requiring even greater specialization among professionals. The flood of new information will necessitate that physicians become interdependent to remain informed about treatments. Specialization in specific domains of neurosurgery will be essential for the neurosurgeon to remain current in the specialty and to provide the best and latest care to his/her patients. Our meetings have already become divided into superspecialty sections; most of these sections also hold independent meetings.

In the academic center, basic scientists, engineers, and magnetic resonance imaging physicists, to name a few, will need to work together with clinicians to develop the advances. Outside the academic center in private practice, neurosurgeons, neurologists, psychiatrists, neuroradiologists, and others will have to share their knowledge to provide the latest and best treatment for their patients.

\section{FUTURE CHANGES IN HEALTH CARE}

The notion of which health care-related changes will become significant to practitioners is a very difficult subject on which to make predictions; however, there are several trends that we believe will continue. At present, a physician can expect to practice for 30 to 40 years after medical school. This assumption, too, may change as life expectancy increases. First, it is obvious that over the past 5000 years of recorded history, and especially in the last 100 years, there have been many quanta of changes in medicine. Life expectancy has doubled in the last 100 years. ${ }^{2}$ A little over 100 years ago, the first craniotomy was performed. Minimally invasive surgery, interventional procedures, and cell program-related genetic manipulation are new therapies physicians and neurosurgeons are learning at the beginning of the 21 st century. In the next 50 years major evolutions in the practice of medicine will continue. Neurosurgeons and physicians should be prepared to be flexible, to learn new approaches, and to adapt to the changes in medicine. These changes will require specialization, and continuing education will become mandatory to keep knowledgeable. All of these changes will be facilitated by high-speed communications among neurosurgeons around the world.

\section{Socialized Medicine}

In every country in the world except the US, medicine is socialized. Over the last 50 years, however, there has been a progressive socialization of medicine in the US. Even though $85 \%$ of the population is served by an outstanding health care system, there will be powerful pressure exerted by the government and the public to find a way to provide service to all. To date, advocates of government control have predominated because those in favor of nonsocialized medicine have failed to provide a reasonable alternative in the private sector. The socialization of medicine in other countries has failed-with long waiting times for care, limited access, and rationing of new advances in medical care-to provide the kind of medical care the citizens of the US have come to expect. There will, however, be a progressive invasion of medicine in the US by governmental bodies, because legislators and the public will ignore the faults of socialized medicine seen in other countries. Most people will want free government-sponsored medicine. Although physicians have a tremendous opportunity to reverse this relentless progress toward socialism by educating the public, doctors and medical societies have thus far failed to counter this socialistic trend successfully.

\section{Responsibility for Health}

One of the major steps physicians can take to reduce the costs of health care is to teach citizens responsibility for their own health. People must realize this responsibility. Requiring some members of the public to pay for the impulsive and unreasonable "life decisions" of others cannot be tolerated. Such behaviors include smoking, improper diet and lack of activity, illicit drug use, alcoholism and drunk driving, carelessness with firearms or cars, and sexual promiscuity. These unhealthy lifestyle choices compromise the provision of health care of those who practice reasonable health behavior as well as increase 
its costs. Fifty percent of all deaths are related to poor health behaviors. ${ }^{11}$ Insurance premiums should be related to health behaviors.

\section{Communications in Health Care}

Our contemporary ability to communicate via the internet and by satellite will increasingly allow physicians to consult their colleagues and experts anywhere in the world about a patient by transferring images and other data in real time. Much of this information will be exchanged using hand-held computer-phones as powerful as desktop computers in use today. Such advances will benefit our patients.

\section{Specialty Hospitals}

Herzlinger ${ }^{4}$ has written about the development of hospitals that will become "focused factories" in the future. In essence, she believes that hospitals at which there is focus on a specific disease can provide a high volume of care, with outstanding results, at a low cost. There are already examples of this practice occurring in health care. Optometry offices are an excellent example. There are also centers in which hernias are exclusively treated. This trend will expand into areas such as stroke, back pain, and movement disorders.

\section{Disease Management}

We will transition from surgically or medically treated diseases to total disease management. Although we tend to focus on the "sensational" diseases such as arteriovenous malformations, aneurysms, and spinal cord injury, there is a far higher incidence of arthritis that appears as radiculopathy, myelopathy, back pain, neck pain, or symptomatic spinal stenosis. Practices should orient to treating these common types of problems, by using teams of specialists from different fields, rather than by concentrating on a surgical or specific type of therapy. By being able to offer different perspectives on the management of a disease, neurosurgeons and their colleagues will see an everincreasing number of patients rather than only a select few who present for a specialized surgical procedure. When one of the authors added an interventional neuroradiologist to his practice, the number of cases with vascular disease increased fivefold. The other author added psychiatrists, psychologists, and physical therapists to his practice and increased the number of patients seeking pain-related treatment, both surgical and medical, while developing a leading clinic on pain management.

\section{Academic Medical Centers Will Change}

Academic medical centers are attempting to provide everything in health care to everybody and are failing nationwide. Clearly individuals at these centers are hoping for a return to a past economic system that will never happen, while refusing to focus on the strategies necessary to succeed in the new system. Community hospitals will become more specialized as physicians just out of residency bring their recently acquired skills and knowledge to the community. Academic center hospitals will become smaller, providing a high level of complex care for difficult cases not available in the community. Academic cen- ters should also be at the forefront of advances in medicine. Because community and academic centers will be connected electronically, patients will receive the benefits of the latest care. Students will be educated in the academic and community setting to benefit from seeing all types of patients. Academic centers will serve as the intensive care hospitals of the future and will therefore have fewer beds.

\section{Educational Programs}

With all of the aforementioned changes and the impact of information technology, simultaneous revisions in the education of medical students, residents, and practicing physicians will be required. New educational methodologies will make profound use of computers and information technology. Surgical simulation models will aid in teaching new techniques to students and physicians. Using specific neuroimages obtained from each patient, surgeons will be able to navigate electronically through the brain, other structures, and organs to reach the surgical target while inducing minimal morbidity. Magnetic resonance imaging-demonstrated anatomy, fiber tracts and their functions, and metabolism will be fused electronically to provide a three-dimensional image of the structure of interest in each patient. We will be able to obtain this information at home or in the office to prepare for the procedure beforehand. The surgeon will also be able to access a library of other surgeons' electronically recorded approaches to the lesion, and thus will gain the greatest possible experience before actually undertaking surgery in the patient. Such educational tools will diminish the surgeon's learning curve and shift experience now learned by apprenticeship to that gleaned through a computer tutorial. These advances will also apply to the minimally invasive approaches used in other specialties. Physicians will access all medical texts and journals electronically, as has recently begun to occur. This information will include anatomical details in three dimensions. Additionally, the public will become increasingly informed because they will have electronic access to similar information as the physicians.

\section{CHANGES IN PRACTICE PATTERNS AS A RESULT OF ADVANCES}

As a result of the aforementioned scientific and health care changes, the successful practice of the future will, by necessity, have several neurosurgeons working together, each specializing in a particular area. A few large clinics in the US are already doing this. To be even more comprehensive, the practice should include specialists in other fields who are knowledgeable about aspects of particular diseases.

To treat the patient who has suffered a stroke, for example, the practice should have a vascular neurologist, interventional neuroradiologist, and a vascular neurosurgeon who can work together to evaluate and treat various aspects of the disease. The specialist will work as a team, discussing and treating the stroke patient. Whether the patient has suffered an ischemic or embolic event or harbors an aneurysm, or arteriovenous malformation, an increasingly collaborative team of such specialists can pro- 


\section{J. I. Ausman and R. P. Pawl}

vide infinitely better care than individual members of the team working independently. This collaborative treatment will yield improved outcomes and lower-cost care, all of which will generate the necessary competitive advantage for the practice in the health care marketplace. ${ }^{4}$

As a second example, to treat patients with complaints of pain, the practice should employ psychiatrists, psychologists, physiatrists, and physical therapists in addition to spine and pain neurosurgeons. The greater the array of specialists working together at a practice, the more incisive will be the insight into the patient's problem.

These nonneurosurgeon specialists will not be limited to treating one disease entity but will be able to lend their expertise to the treatment of several. For example, the psychiatrist will be able to serve the patient with stroke, movement disorder, and spine and peripheral nerve problems.

\section{ORGANIZATION OF THE NEUROSURGICAL PRACTICE FOR TOMORROW}

\section{Initial Steps}

An understanding of the aforementioned trends in science leads to the conclusion that the individual practice of medicine is no longer a viable option. Thus, group practice is inevitable. To be very successful, the group practice should probably initially be formed by at least three neurosurgeons, and the practitioners should plan to expand beyond that number to include many neurosurgeons and other specialists. As an alternative, neurosurgeons competing separately in private practices within a community could combine offices to form a larger group, although this is not easy, because each neurosurgeon has to understand that some degree of independence must be sacrificed to achieve greater group power. This step is particularly difficult for neurosurgeons who are older, less flexible, or were trained in a program in which collaboration with other specialists was not emphasized. Neurosurgeons who form a group practice must understand the needs of the group or they will not be effective participants. In Chicago, we attempted this type of amalgamation of academic and practicing neurosurgeons, but the success has been limited because the participating neurosurgeons were reluctant to surrender some of their independence to a group.

\section{Expanding the Practice}

The market served by the practice will not only include the city in which it originated but will extend to communities within a 50- to 100-mile radius. The practice will then have a larger population to occupy its specialists. The practice should provide diversified neurological care to a regional population. Such specialization will permit cross coverage, leaving more time for individual practitioners to devote to reading, continuing education, and research. Distant sites will be connected by closed-circuit television. Digitized imaging and real-time interfaces between the distant sites and the specialists will ensure improved care of patients further away from the main center. Nurse practitioners, also members of the expanded practice, will be able to see the patients in the hospitals and in the dis- tant sites on a regular basis, allowing the specialists to devote more of their time to other activities.

\section{Billing, Purchasing, and Administration}

Given the higher number of physicians and paramedical personnel in the practice, it is logical for it to have its own billing and collection team. An office manager will be essential to run the main office and its branches, as will other personnel to oversee the technological facets of the practice. The group practice will have leverage in the market to bargain with suppliers, because large quantities of items will be required for its offices and associated hospitals. This market power will reduce the costs to both the practice and the hospital and can be used by the practice to obtain benefits from the hospital.

\section{Should the Practice Own and Operate a Hospital?}

At least two physician groups in the US already own hospitals. The risk of owning a hospital is that the physician owners may feel pressed to fill the hospital beds with patients, which would negatively affect their practice of medicine. Other groups have succumbed to this pressure.

\section{How the Partners Should Divide the Labor}

In addition to the science of medicine, there are other issues that may be equally important to the survival of the group. Here, too, a division of labor allowing partners to specialize in nonscientific endeavors will be successful. Partners should be designated to establish the proper practice guidelines and to oversee the defense of the partners who are sued for malpractice. Other partners should be responsible for the finances of the practice, working with the business manager. Another group of partners might be involved in developing a strategy for growth. Additional duties can be delegated once they become apparent.

It is also important for the members to be involved in the politics of medicine. All should be members of their respective local medical societies, as well as county, state, or national societies. In these organizations, as in the hospital, the doctors' interests must be represented or it will be left to others who may not have the best interests of the practice in mind.

\section{Patient Conferences Among the Staff Members}

One of the most crucial activities in shaping the character of the practice is to hold regularly scheduled patient conferences. All staff members, medical and paramedical (except administrative assistants), must attend, if not in person then by phone. There should be a daily list of all inpatients in all of the hospitals served. The list should contain the diagnoses, locations, referring physician, age, record number, and critical events for each patient as well as pertinent dates during the hospital stay. All cases should be reviewed. One member should assume leadership, preferably the senior member of the practice. Each case should be discussed briefly and the opinions of the multidisciplinary staff sought. The purpose of this conference is to generate team spirit in managing each patient and to provide the widest possible input for that patient's care. Although the conference may require 1 hour or more, the rewards to the practice and its members will be multiple. 
Such conferencing ensures that the practice's "products," the results of each physician's efforts, are at the highest level of quality; numerous mistakes are prevented and much is learned. The team leader should provide the balance, and assure that the truth is always told. If criticism is necessary, it can be appropriately given at that time. This type of conference is the glue that holds the practice together. Operating schedules and other issues can also be worked out at this time. The meeting must move quickly so that all feel that it is a worthwhile investment of their time.

Unfortunately, this is the first conference to be cancelled as people consider these suggestions, but it is a fatal mistake to do so. Remember that the aforementioned future trends stress interdependence and knowledge sharing as a way to overcome the tremendous growth of information in all specialties. In the university setting the conference is held every day, also as a teaching device for the residents. In the practice setting scheduling will have to be adjusted to the demands of the practice, but the conference should be held no less than once a week.

\section{Should the Practice Become Involved in Research?}

The practice should adopt standards of care for its patients based on the latest scientific information. Because the practice will have a computer-based record system for following its high number of patients, at a minimum it will be able to supply data on its clinical care-related outcomes. The practice should collaborate with an academic center, participating in scientific research. Such efforts will broaden the scientific knowledge of the partners and ultimately benefit their patients.

Neurosurgeons in academic medical centers must also realize that they, too, can benefit by maintaining an association with practicing neurosurgeons. Too often the practicing neurosurgeon is viewed as a threat to the academician or vice versa because neither recognizes his/her role in the partnership. The academician should be committed to making new discoveries that can be translated into advances in patient care. The academic medical center should be the place in which a patient receives treatment not available in the community. Those community-provided services should be available close to the patient's home. Advanced communications technology will connect the academic center and the practice making consultation instantly possible and benefiting the patient.

The academician and the practicing physician need each other and should share their knowledge and experience for the benefit of their patients. Unfortunately, this ideal is not often reached because each is more concerned with survival than the patient's best interests. Those at academic centers and practitioners who realize that cooperative partnership is best for patients and medicine will ultimately provide a blueprint for others.

\section{How to Deal with the Egocentric Problem}

If there is a single factor that causes a practice to fail or impedes its expansion, it is the egocentrism of the individuals forming the original group. It is admirable to recruit entrepreneurial partners, but the survival of the group must transcend any individual member. All partners must agree to work as a team. The aforementioned tenet must be understood and uniformly accepted; otherwise, the original goal will never be achieved and the group will not survive.

The concept of teamwork should be instilled in the student in medical school and residency education programs. Residency programs will need to change in the future to accommodate the new realities of team-based medicine as opposed to specialty competition.

\section{Financial Motivations}

The desire for money will be a constant force leading to the success or failure of a practice. Socialism in any form will not work as a model of practice governance. Each individual must be rewarded for his or her contribution to the practice. Some years ago, one of the authors (J.I.A.) devised a simple point system that rewarded partners for every activity necessary to make each practice run successfully. Points were given based on clinical productivity and on time spent in administrative tasks, political events, research, and lecturing. The system worked exceptionally well. Everyone understands that his or her activities will be rewarded even if they are not purely clinical. Recognition of these nonclinical activities provides incentive for partners to contribute in nonclinical areas. It is crucial to remember that for an incentive system to work it must be fair and easily understood by all. The goal of the practice is to be so busy that no partner is concerned about giving work to another. Thus, money never becomes an issue.

\section{Leadership in the Practice}

To begin, the multidisciplinary nature of the practice is identified as including neurosurgeons, neurologists, neuropsychiatrists, neuropsychologists, physiatrists, and others. Should the practice also include internists and other nonneuroscience specialists? It certainly can, depending on how the practice evolves. The precedent does exist; there are a number of multidisciplinary clinics in the US that have been in existence for many years. A physician should be in charge of the practice in all cases. Most likely, that physician will eventually obtain a business degree or business training of some type. In our opinion, one of the reasons for the failure of academic centers and hospitals today is that nonphysicians manage these enterprises. No one knows the future of medicine better nor the investments essential for the health of the practice and its patients than a physician. The physician administrator must continue to practice medicine so that he/she has daily contact with the patients, their problems, and other practitioners serving the patients within the existing system.

\section{THE FUTURE OF THE ACADEMIC OR MAJOR MEDICAL CENTER}

Solving the problem of the future-oriented strategy for the academic or major medical center may not be as easy as for community practices because the bureaucracy involved in the academic center may prevent it from being as entrepreneurial and innovative as a practice. Resistance to change is also inherent in academic centers, where academicians believe that they are at the forefront of change. 
This latter belief may be true scientifically in the academic center but is not true for their willingness to change strategically and organizationally.

\section{Research is the Academic Medical Center's Strategic Advantage}

For the academic center to survive in the future, there is only one strategy that will work: to be deeply involved in research that will expand and define the future of the specialty and medicine. Academic medical centers fail to understand that the resident physicians of today will be the practitioners of tomorrow, competing with the academic center in its community. Thus, the academic center must continue to change so that it will stay ahead of the graduates entering practice.

\section{Other Advantages at the Academic Medical Center}

The academic medical center has several other advantages over the large practice in the community or the community hospital. The academic center has a large staff of clinical specialists and superspecialists in addition to basic scientists. In the event of any particular problem, the academic center can call on superspecialists in multiple fields 24 hours a day. Furthermore, the academic center has a resident staff on call at all times. These benefits must be leveraged to the advantage of the academic center. In many cases this leverage is not utilized.

The future academic medical center will continue to be the breeding ground for scientific advances in biology and technology. The members of the academic community should realize that they, too, would need to surrender some independence to work together as a team to achieve scientific discoveries. This group integration will be required because of the rapid and profound advances in science. Such arrangements also will require a different view of compensation, with more sharing among team members than occurs now. This team approach to diseases will attract more patients to the team and to the center.

\section{MAKING DECISIONS IN A DIVERSE GROUP OF PROFESSIONALS}

\section{Leadership or Management}

Excellence in any endeavor is never achieved by frustrating innovation, creativity, and entrepreneurial activity. In medical centers, medical societies, and medicine in general, however, consensus has become the method of providing direction for such organizations. Consensus management is a manager's excuse for not taking responsibility for any decision. Imagine creating a great painting, designing a futuristic building, writing a symphony, or even performing an operation by consensus. Yet medical centers today are governed by consensus.

\section{Psychology of Group Members and Interactions}

In leading a diverse group of physicians and scientists, the backgrounds of some participants may predispose them to leadership. The orientation of most nonsurgical specialists is diametrically opposed to that of surgical specialists, primarily because of differences in specialty education. Surgeons treat structural disease that is easily rec- ognized, well defined, and has specific methods of management. Internists and other nonsurgeons treat disease that is often diffuse, difficult to diagnose, and has various possible treatments because the disease process is so slow to unfold and variable in its manifestations.

Thus, medical education attracts and produces physicians with different orientations toward the problems they face. These differences in education also influence the decisions physicians make in organizations and on committees. Surgeons demand quick decisions, whereas nonsurgeons take longer to reach a decision and often embrace consensus-derived decisions. These differences can lead to conflict and delays in the decision-making process. At this juncture, the leader may be required to make the decision, ideally based on the strategic direction and goals of the organization.

In the business world in which practices compete, decisions are made with a "surgical" orientation. In the political world, they are made by consensus because the problems are not as clearly defined and the goal is to please the greatest number of people. It is important to recognize these differences in decision-making styles when leading a diverse organization. Additionally, physicians have not been educated in the nuances of politics, marketing, or the business world. This lack of education becomes a disadvantage because the practice and the academic center are competing in a business environment with insurance companies and industry. These business entities, coupled with the government, influence the direction of health care. Their members think differently from the physician who is the advocate for the patient and not for the company bottom line. Most physicians are idealists and purists in their approach to medicine, whereas pragmatism and financial gains drive the business world. To compete in a business world, physicians must do so on business terms while always placing the interests of the patient first. To achieve this goal, there should be sound business plans, marketing plans and strategic plans for any medical organization, all of which are grounded in what is best for the patient. The operation of a medical organization should be based on these principles, not on politics. No business will succeed in which politics prevail in decision making, which is common in academic centers and is a fundamental reason for their failure in a business competition.

\section{LEADERSHIP BY PRINCIPLE AND VISION OR MANAGEMENT BY CONSENSUS}

In any medical organization, those with vision and creativity should be supported whereas those without these talents should not be rewarded. Excellence should be the primary goal in any endeavor. In medicine this means providing the patient with the best solution available for his or her problem. The pursuit of excellence does not entail compromise with politics, government regulations, or hospital rules.

Leadership requires creativity, devotion to principle, vision, and entrepreneurship. People who possess these traits should be chosen to lead organizations, medical centers, and practices. The only alternative is compromise, consensus, and voluntary mediocrity. No organization can ever succeed by following this strategy. Thus, in imple- 


\section{Success in tomorrow's scientific and socioeconomic environment}

menting a strategy for shaping a future practice, the most critical decisions are 1) to choose a leader and 2) to refuse to accept any compromise in excellence. Excellence should be pursued and the patient put first. These are the principles for success in the future. If you were the patient, would you not want your provider to pursue such endeavors?

\section{Acknowledgment}

The authors wish to thank Amy Akers for her editorial assistance in preparing this manuscript.

\section{References}

1. Apuzzo MJ, Liu CY: 2001: Things to come. Neurosurgery 49: 765-778, 2001

2. Becker GS: Longer life was the century's greatest gift. Bus Week Online: January 31, 2000 (http://www.businessweek. com/archives/2000/b3666076.arc.htm) [Accessed 13 March 2002]

3. Cetron MJ, Davies O: Trends now changing the world: technology, the workplace, management and institutions. Futurist 35:27-42, 2001

4. Herzlinger RE: Market-Driven Health Care: Who Wins, Who Loses in the Transformation of America's Largest Service Industry. New York: Persus Books Group, 1999

5. Kimbrell TA, Ketter TA, George MS, et al: Regional cerebral glucose utilization in patients with a range of severities of unipolar depression. Biol Psychiatry 51:237-252, 2002

6. Mamata H, Mamata Y, Westin CF, et al: High-resolution line scan diffusion tensor MR imaging of white matter fiber tract anatomy. AJNR 23:67-75, 2002

7. Martin NA, Patwardhan RV, Alexander MJ, et al: Characterization of cerebral hemodynamic phases following severe head trauma: hypoperfusion, hyperemia, and vasospasm. J Neurosurg 87:9-19, 1997

8. Roitberg B: Research news and notes. Surg Neurol 57:3-4, 2002

9. Rosenberg RN: Genomic neurology: a new beginning. Arch Neurol 58:1739-1741, 2001

10. Service RF: Breakthrough of the year. Molecules get wired. Science 294:2442-2443, 2001

11. Steen RG: Winning the war on cancer. Futurist 31:24-28, 1997

12. Thompson TP, Lundsford LD, Kondziolka D: Restorative neurosurgery: opportunities for restoration of function in acquired, degenerative, and idiopathic neurological diseases. Neurosurgery 45:741-752, 1999

13. Zubieta JK, Smith YR, Bueller JA, et al: Regional mu opiod receptor regulation of sensory and affective dimensions of pain. Science 293:311-315, 2001

Manuscript received February 19, 2002.

Accepted in final form March 8, 2002.

Address reprint requests to: James I. Ausman, M.D., Ph.D., 70950 Fairway Drive, Rancho Mirage, California 92270. email: jausman@uic.edu. 